\title{
Ambit determination method in estimating rice plant population density
}

\author{
*Abu Bakar, B., Abdul Rahman, M.S., Teoh, C.C., Abdullah, M.Z.K. and Ismail, R. \\ Engineering Research Centre, MARDI Headquarters, P.O. Box 12301, 50774 Kuala Lumpur, Malaysia
}

\author{
Article history: \\ Received: 16 October 2017 \\ Received in revised form: 6 \\ November 2017 \\ Accepted: 7 November 2017 \\ Available Online: 18 \\ November 2017

\section{Keywords:} \\ Automation, \\ Population density, \\ Precision farming, \\ Rice production, \\ Sensor
}

DOI:

https://doi.org/10.26656/fr.2017.2(2).253

\begin{abstract}
Rice plant population density is a key indicator in determining the crop setting and fertilizer application rate. It is therefore essential that the population density is monitored to ensure that a correct crop management decision is taken. The conventional method of determining plant population is by manually counting the total number of rice plant tillers in a $25 \mathrm{~cm} \times 25 \mathrm{~cm}$ square frame. Sampling is done by randomly choosing several different locations within a plot to perform tiller counting. This sampling method is time consuming, labour intensive and costly. An alternative fast estimating method was developed to overcome this issue. The method relies on measuring the outer circumference or ambit of the contained rice plants in a $25 \mathrm{~cm} \mathrm{x} 25 \mathrm{~cm}$ square frame to determine the number of tillers within that square frame. Data samples of rice variety MR219 were collected from rice plots in the Muda granary area, Sungai Limau Dalam, Kedah. The data were taken at 50 days and 70 days after seeding (DAS). A total of 100 data samples were collected for each sampling day. A good correlation was obtained for the variety of 50 DAS and 70 DAS. The model was then verified by taking 100 samples with the latching strap for 50 DAS and 70 DAS. As a result, this technique can be used as a fast, economical and practical alternative to manual tiller counting. The technique can potentially be used in the development of an electronic sensing system to estimate paddy plant population density.
\end{abstract}

\section{Introduction}

Paddy or rice plant is one of the major agro-food commodities in Malaysia with a planted area of 689,732 hectares and a production of about 2.6 million tonnes nationwide in 2014 (MOA, 2014). This represented a production value of about RM 1.98 billion. The selfsufficiency level in Malaysia for this crop hovered around $70 \%$ from the year 2008-2014 with an average yield of 3.8 tonnes per hectare (MOA, 2014).

The National Agrofood Policy (NAP) 2011-2020 was introduced by the government to address three main issues; food supply and safety, competitiveness and sustainability of the industry, and increasing the income level of its target groups (MOA, 2011). For these reasons, MARDI has developed the precision farming technology package for paddy (Chan, 2013). It incorporates information and technology to achieve sitespecific crop management (Mooney et al., 2009; Kutter et al., 2009; Bakhtiari and Hematian, 2013). One of the important components in precision farming is the monitoring of plant population density.
Rice plant population density is a key indicator in crop management (Othman et al., 2005; Safdar Baloch et al., 2007). It provides information on the status of the crop as well as potential yield. This allows farm managers to make calculated decisions on the amount of fertilizer and pesticide to use. It not only saves cost but also reduces the impact on the environment. Therefore monitoring the population density is essential (Miller et al., 1991; Islam et al., 2013).

The conventional method of determining plant population is by manually counting the total number of rice plant tillers in a $25 \mathrm{~cm} \times 25 \mathrm{~cm}$ square frame (Oghalo, 2011). Sampling is done by randomly choosing several different locations within a plot to perform tiller counting. This sampling technique is time consuming, labour intensive and costly. It is, therefore, necessary that a new sampling method be developed to alleviate the above issues.

There has been effort to exploit image processing techniques to determine the plant population density (Kurosu et al., 1995; Tan et al., 2006; Lim et al., 2007; 
Pentjuss et al., 2011). The methods used range from simple off the shelf cameras to more sophisticated equipment such as multi-band radar and satellite imagery. Closer to home, an automatic counting method to estimate rice plant population through an image processing technique was reported in (Teoh et al., 2008). Digital images of rice plants in a $25 \mathrm{~cm}$ x $25 \mathrm{~cm}$ square frame were captured and classified into the plant and non -plant regions. Linear regression analysis was used to determine the correlation between plant tiller count and the area of plant region. It was found that a high correlation coefficient value of 0.8328 existed between the two parameters.

The method mentioned above has several weaknesses. It does not take into account the noise caused by the natural surroundings. The area of plant region was classified using red $(R)$, green $(G)$ and blue (B) bands. Rice plants are usually partially submerged in water. The reflectance of sunlight on the water distorts the images acquired and add significant noise to the bands. The non-uniformity of ambient lighting also causes inconsistent images where the same sample taken at two moments in time might have a totally different plant region area. Moreover, the images must be taken at a constant height above the ground for the region of interest to be consistent. This is not trivial in a rice field due to the soft ground. Therefore, a faster simpler approach is needed.

The aim of this research is to explore an alternative method to estimate the rice plant population density which would address the issues mentioned above. It seeks to study the correlation between the total circumference of the rice plants within the $25 \mathrm{~cm} \times 25$ $\mathrm{cm}$ square frame and the plant count. This work further proposes a potential electronic sensor system that eliminates unnecessary dependency on ambient conditions as a result of the current findings.

\section{Materials and methods}

\subsection{Paddy sampling}

The sampling was done by collecting data of random paddy plants from variety MR219in the Muda granary area, Sungai Limau Dalam, Kedah. The samples were taken at 50 days and 70 days after seeding. A total of 100 data samples were collected at each sampling day.

\subsection{Population density determination}

A $25 \mathrm{~cm} \times 25 \mathrm{~cm}$ square frame was placed randomly in the paddy plot. All the plant tillers contained in the square frame were counted manually and recorded. After manual counting of tillers in a square frame was completed, a $30 \mathrm{~cm}$ latching strap made of nylon with $0.5 \mathrm{~cm}$ diameter holes drilled every $1 \mathrm{~cm}$ was then used to bunch up the tillers. The latching strap has a flexible tape section with teeth that engage with a pawl in the head to form a ratchet so that as the free end of the tape section is pulled the strap tightens and does not come undone until a tab is depressed to release the ratchet so that the tape can be loosened or removed. Figure 1 shows the construction of the latching strip.

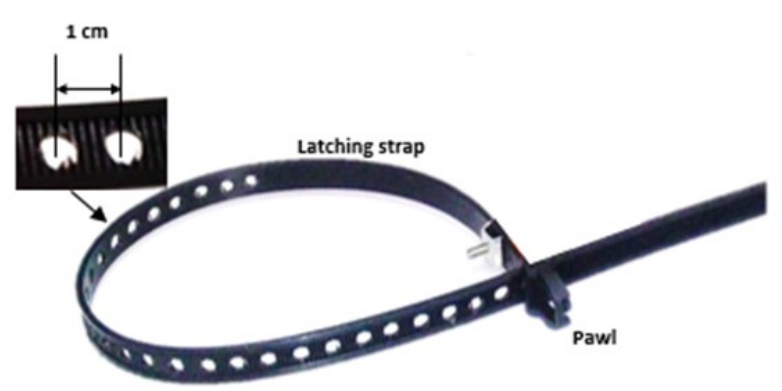

Figure 1. Latching strap. Holes drilled $1 \mathrm{~cm}$ apart.

\subsection{Statistical analysis}

The open source software environment for statistical computing $\mathrm{R}$ was used to analyse the relationship between the circumference of the tillers and the plant count number in the square frame. A linear model was developed that had circumference of tillers as the independent variable and plant count number as the dependent variable. A hypothesis test ( $t$-test) was conducted to show the linear association between the two variables. A confidence interval was calculated to prove the adequacy of the model for the data. A plot of residuals versus independent values was used to validate certain assumptions about the data.

\section{Results and discussion}

The number of manually counted tillers and the circumference was recorded and used to determine the relationship between the variables. The circumference was taken by bunching the tillers in the $25 \mathrm{~cm} \times 25 \mathrm{~cm}$ square frame with the latching strap. The strap was then tightened and the number of holes that passed through the pawl was recorded. The circumference was determined by multiplying the number of holes recorded by $1 \mathrm{~cm}$ and subtracting it from $30 \mathrm{~cm}$ (the total length of the strap). The measurements were taken about $10 \mathrm{~cm}$ from the ground. Figure 2 shows the scatter plots for the data collected at 50 days and 70 days after seeding (DAS).

In order to see whether a linear relationship exists for the whole population, the $t$-test which is given in equation (1) was used to test the following null hypothesis $H_{0}: \beta_{1}=0$ against an alternative hypothesis $H_{\mathrm{A}}: \beta_{1} \neq 0$ where $\beta_{1}$ is the slope parameter.

$$
t_{\mathrm{k}}=\frac{\hat{\beta}_{1}^{\mathrm{k}}}{\sec \left(\hat{\beta}_{1}^{\mathrm{k}}\right)}
$$


Tiller Count vs. Circumference at 50 DAS

Tiller Count vs. Circumference at 70 DAS
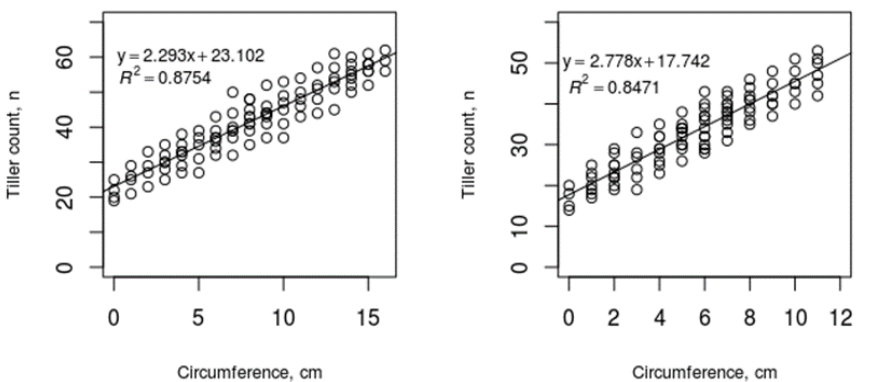

Figure 2. Scatter plots of data collected at 50 days and 70 days after seeding (DAS).

In equation (1), $t_{k}$ is the test statistic at $\mathrm{k}$ days after seeding, $\hat{\beta}_{1}^{\mathrm{k}}$ is the corresponding estimate of the slope parameter $\beta_{1}{ }^{\mathrm{k}}$ at $\mathrm{k}$ days after seeding and s.e. $\left(\hat{\beta}_{1}^{\mathrm{k}}\right)$ is the standard error of the estimate $\beta_{1}{ }^{\mathrm{k}}$. The

statistic $t_{k}$ is distributed as a Student's $t$ with $(n-2)$ degrees of freedom where $n$ in our case is 100. A simple linear regression analysis was run in $\mathrm{R}$ for both cases. For the case of $\mathrm{k}=50 \mathrm{DAS}$, the analysis obtained the test statistic $\mathrm{t}_{50}=26.24$. The $p_{50}$-value calculated by $\mathrm{R}$ was $2.2 \times 10^{-16}$. The $p_{\mathrm{k}}$-value is the probability that a random variable having a Student $t$ distribution with $(n-2)$ degrees of freedom is greater than $\left|t_{k}\right|$ (the absolute value of the test statistic at $\mathrm{k}$ days after seeding). There was compelling evidence, at the significance level $\alpha=0.001$, to reject the null hypothesis $H_{0}{ }^{50}$ in favour of the alternative hypothesis $H_{\mathrm{A}}{ }^{50}$ and conclude that slope parameter $\beta_{1}{ }^{50}$ does not equal 0 .

For the case of $\mathrm{k}=70 \mathrm{DAS}$, the analysis obtained the test statistic $\mathrm{t}_{70}=23.3$. The $p_{70}$-value calculated by $\mathrm{R}$ was $2 \times 10^{-16}$. There was compelling evidence, at the significance level $\alpha=0.001$, to reject the null hypothesis $H_{0}{ }^{70}$ in favour of the alternative hypothesis $H_{\mathrm{A}}{ }^{70}$ and conclude that slope parameter $\beta_{1}{ }^{70}$ does not equal 0 .

A least squares regression line was fitted for each scatter plot. The models are described by the following equations:

$$
\begin{aligned}
& y^{50}=2.29 x^{50}+23.1 \\
& y^{70}=2.78 x^{70}+17.74
\end{aligned}
$$

In equation (2) and equation (3) above, $y^{\mathrm{k}}$ is the tiller count and $x^{\mathrm{k}}$ is the circumference of the bunched tillers at $\mathrm{k}=50 \mathrm{DAS}$ and $\mathrm{k}=70 \mathrm{DAS}$ after seeding respectively. It can be seen that the above the equations are different for both days. This was expected due to the different growth stages of the plants.

The evaluation of the models was done by assessing whether the assumptions underlying the models seem reasonable when applied to the datasets in question. The first assumption of this simple linear regression model was that the mean of the dependent variable, $\mathrm{E}\left(Y_{\mathrm{i}}\right)$ (tiller count) at each value of the independent variable, $x_{\mathrm{i}}$ (circumference) is a linear function of the independent variable $x_{\mathrm{i}}$. The second assumption was that the error terms of the dependent variable $\varepsilon_{\mathrm{i}}$ are independent. The third assumption was that the error terms at each value of the independent variable $x_{\mathrm{i}}$ are normally distributed. The last assumption was that the error terms has equal variance $\sigma^{2}$ at each value of $x_{\mathrm{i}}$.

Figure 3 shows the residuals versus fit plots for the data collected at $\mathrm{k}=50 \mathrm{DAS}$ and $\mathrm{k}=70 \mathrm{DAS}$. It can be seen from the figures that the residuals are randomly scattered around the 0 horizontal line. This suggests that the first and fourth assumptions detailed above were reasonable.
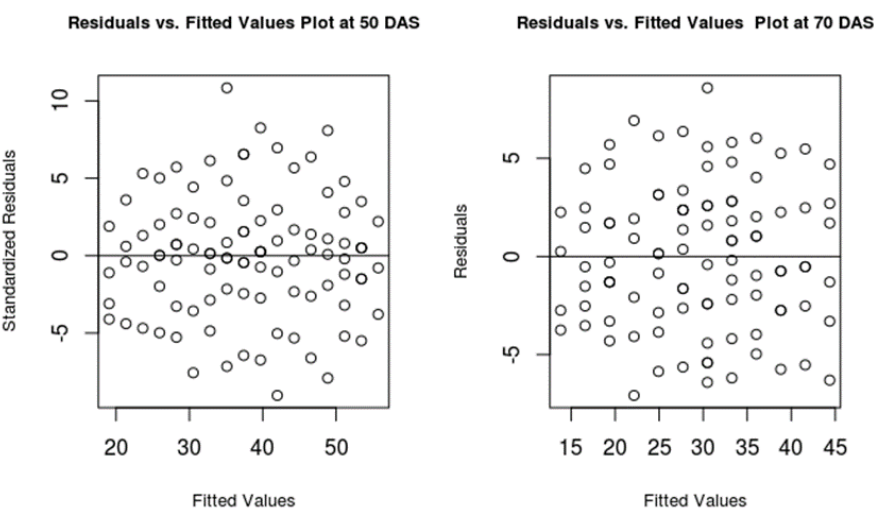

Figure 3. Residuals versus fit plots for 50 days and 70 days after seeding (DAS).

The plots of residuals versus order and normal probability plots of the residuals for the data collected at $\mathrm{k}=50 \mathrm{DAS}$ and $\mathrm{k}=70 \mathrm{DAS}$ were generated but are not shown for the sake of brevity. It was concluded from the residuals versus order plots that the residuals are scattered around the residual $=0$ line. This suggests that the second assumption detailed above was reasonable. After analysis of the normal probability plots of the residuals, it was concluded that the relationship between the normal scores and residuals are approximately linear. The plots suggest that the third assumption of the models was reasonable. The assessment of the assumptions described above led to the conclusion that the datasets at both 50DAS and 70DAS seeding can be described well by the developed models.

The developed linear models were verified by a taking 100 samples with the latching strap for each day after seeding (50DAS and 70DAS) from a rice plot in Sungai Limau Dalam, Kedah. The circumference of each sample was used in the developed models to estimate the number of tillers. Table 1 and Table 2 summarize the percentage of accuracy of the prediction compared to the actual number of tillers for both models. For $\mathrm{k}=50 \mathrm{DAS}$ and $\mathrm{k}=70 \mathrm{DAS}$, the accuracy of prediction models was found to be $85.9 \%$ and $84.2 \%$ respectively. The accuracy of the method developed in this work was slightly lower compared to the method developed by (Teoh et al., 
2008). However, due to the weaknesses of the latter method which was discussed in the introduction section, the method developed here is preferable due to its reliability and quickness of measurement. Moreover, the accuracy of the presented method could be improved by sampling data over several seasons to seek a better generalization of the model. Therefore, the technique in the current work can be used as a fast, economical and practical alternative to manual tiller counting.

\section{Conclusion}

This work described a fast alternative method of estimating rice plant population density. The density was determined by the circumference of the tillers bunched by a latching strap. Two linear regression models were developed for 50 days and 70 days after seeding respectively. An assessment of the underlying model assumptions showed that the models were suitable for the dataset. The models will be used to develop an electronic sensing system where a photoelectric sensor is attached at the head of the pawl. It then sends an electronic pulse signal to a processor every time a change of state (hole/ no hole) is detected. A processor module will compute the number of tillers based on the developed model which accepts the total number of pulses detected as the input.

\section{Acknowledgement}

The research work was funded by MARDI short term grant (JP/RM/0478).

\section{References}

Bakhtiari, A.A. and Hematian, A. (2013). Precision Farming Technology, Opportunities and Difficulty. International Journal for Science and Emerging Technologies with Latest Trends, 5(1), 1-14.

Chan, C.W. (2013). Precision Agriculture: The Way Forward in Mechanised Agriculture. Malaysia: Malaysian Agricultural Research and Development Institute (MARDI).

Islam, M.S., Rashid, M.M., Mondal, M.K., Nath, S.C. and Karim, M.R. (2013). Effect of Planting Density on the Performance of Hybrid Rice (Oryza sativa L.) under Waterlogged Condition. The Agriculturists, 11 (2), 109-113.

Kurosu, T., Fujita, M. and Chiba, K. (1995). Monitoring of rice crop growth from space using the ERS-1 Cband SAR. IEEE Transactions on Geoscience and Remote Sensing, 33(4), 1092-1096. https:// doi.org/10.1109/36.406698.

Kutter, T., Tiemann, S., Siebert, R. and Fountas, S. (2009). The role of communication and co-operation in the adoption of precision farming.Precision Agriculture, 12(1), 2-17. https://doi.org/10.1007/ s11119-009-9150-0.

Lim, K.-S., Tan, C.-P., Koay, J. Y., Koo, V. C., Ewe, H. T., Lo, Y.-C. and Ali, A. (2007). Multitemporal CBand Radar Measurement on Rice Fields. PIERS Online, 3(1), 44-47. https://doi.org/10.2529/ PIERS060904212430.

Miller, B.C., Hill, J.E. and Roberts, S.R. (1991). Plant Population Effects on Growth and Yield in WaterSeeded Rice. Agronomy Journal, 83(2), 291-297. https://doi.org/10.2134/ agronj1991.00021962008300020006x

MOA. (2011). Dasar agromakanan negara 2011-2020. Malaysia: Percetakan Watan Sdn. Bhd.

MOA. (2014). Agrofood statistics 2014. Putrajaya, Malaysia: MOA.

Mooney, D.F., Larson, J.A., Roberts, R.K. and English, B.C. (2009). When does variable rate technology for agricultural sprayers pay? A case study for cotton production in Tennessee. Journal of the American Society of Farm Managers and Rural Appraisers, 177-187.

Oghalo, S.O. (2011). Effect of Population Density on the Performance of Upland Rice (Oryza Sativa) in a Forest-Savanna Transition Zone. International Journal of Sustainable Agriculture, 3(2), 44-48.

Othman, S., Abd. Razak, H. and Rukunudin, I.H. (2005). CREST-FERTO: A decision support system for crop setting and fertilizer management to achieve sustainable target yield performance in precision farming.Proceedings of the national conference on AgriICT. Kuala Lumpur, Malaysia.

Pentjuss, A., Zacepins, A. and Gailums, A. (2011). Improving precision agriculture methods with multiagent systems. Vol. 10, p. 109-114. Proceeding of Engineering for Rural Development, 26 - 27 May, Jelgava

Tan, C.P., Koay, Y.J., Lim, K.S., Bahari, S., Ewe, H.T. and Chuah, H.T. (2006). Applications of remote sensing in the monitoring of rice crops. Journal The Institution of Engineers, Malaysia, 67(4), 1 -10.

Safdar Baloch, M., Awan, I.U., Hassan, G. and Zubair, M. (2007). Studies on Plant Population and Stand Establishment Techniques for Increasing Productivity of Rice in Dera Ismail Khan, Pakistan. Rice Science, 14(2), 118-124. https:// doi.org/10.1016/S1672-6308(07)60017-1

Teoh, C.C., Syaifudin, A.R.M., Isa, O.M. and Abu Bakar, B. (2008). Estimation of rice plant population using digital image processing technique. Journal of Tropical Agriculture and Food Science (JTAFS), 36 (2). 
Table 1. Accuracy of the linear model to estimate number of tillers for $\mathrm{k}=50 \mathrm{DAS}$

\begin{tabular}{|c|c|c|c|c|c|c|c|}
\hline Samples & $\begin{array}{c}\text { Actual tiller } \\
\text { number }\end{array}$ & $\begin{array}{c}\text { Predicted } \\
\text { tiller number }\end{array}$ & $\begin{array}{c}\text { Accuracy } \\
(\%)\end{array}$ & Samples & $\begin{array}{c}\text { Actual tiller } \\
\text { number }\end{array}$ & $\begin{array}{c}\text { Predicted } \\
\text { tiller number }\end{array}$ & $\begin{array}{c}\text { Accuracy } \\
(\%)\end{array}$ \\
\hline 1 & 43 & 49.23 & 85.51 & 51 & 41 & 36.98 & 90.19 \\
\hline 2 & 25 & 31.21 & 75.16 & 52 & 40 & 48.33 & 79.18 \\
\hline 3 & 21 & 22.13 & 94.62 & 53 & 52 & 45.29 & 87.09 \\
\hline 4 & 50 & 42.41 & 84.82 & 54 & 42 & 38.74 & 92.24 \\
\hline 5 & 33 & 27.79 & 84.21 & 55 & 35 & 30.81 & 88.03 \\
\hline 6 & 55 & 49.65 & 90.27 & 56 & 60 & 52.96 & 88.27 \\
\hline 7 & 48 & 50.21 & 95.40 & 57 & 33 & 28.55 & 86.52 \\
\hline 8 & 42 & 37.53 & 89.36 & 58 & 36 & 30.12 & 83.67 \\
\hline 9 & 35 & 39.43 & 87.34 & 59 & 25 & 32.10 & 71.60 \\
\hline 10 & 31 & 22.45 & 72.42 & 60 & 42 & 38.85 & 92.50 \\
\hline 11 & 25 & 21.87 & 87.48 & 61 & 40 & 41.74 & 95.65 \\
\hline 12 & 42 & 36.43 & 86.74 & 62 & 23 & 20.46 & 88.96 \\
\hline 13 & 47 & 53.11 & 87.00 & 63 & 21 & 23.19 & 89.57 \\
\hline 14 & 60 & 53.72 & 89.53 & 64 & 36 & 30.74 & 85.39 \\
\hline 15 & 22 & 26.85 & 77.95 & 65 & 29 & 25.84 & 89.10 \\
\hline 16 & 53 & 63.32 & 80.53 & 66 & 33 & 28.17 & 85.36 \\
\hline 17 & 41 & 37.66 & 91.85 & 67 & 31 & 37.25 & 79.84 \\
\hline 18 & 35 & 29.28 & 83.66 & 68 & 50 & 56.32 & 87.36 \\
\hline 19 & 36 & 40.22 & 88.28 & 69 & 52 & 47.15 & 90.67 \\
\hline 20 & 38 & 35.15 & 92.50 & 70 & 43 & 39.12 & 90.98 \\
\hline 21 & 52 & 50.95 & 97.98 & 71 & 41 & 46.33 & 87.00 \\
\hline 22 & 55 & 48.74 & 88.62 & 72 & 49 & 42.13 & 85.98 \\
\hline 23 & 57 & 62.82 & 89.79 & 73 & 39 & 32.49 & 83.31 \\
\hline 24 & 19 & 19.63 & 96.68 & 74 & 38 & 47.21 & 75.76 \\
\hline 25 & 48 & 42.41 & 88.35 & 75 & 25 & 20.36 & 81.44 \\
\hline 26 & 36 & 42.11 & 83.03 & 76 & 21 & 23.65 & 87.38 \\
\hline 27 & 31 & 28.68 & 92.52 & 77 & 23 & 21.30 & 92.61 \\
\hline 28 & 39 & 45.03 & 84.54 & 78 & 28 & 26.81 & 95.75 \\
\hline 29 & 59 & 51.52 & 87.32 & 79 & 40 & 49.82 & 75.45 \\
\hline 30 & 37 & 30.12 & 81.41 & 80 & 45 & 51.64 & 85.24 \\
\hline 31 & 41 & 49.81 & 78.51 & 81 & 42 & 36.75 & 87.50 \\
\hline 32 & 49 & 57.36 & 82.94 & 82 & 44 & 49.82 & 86.77 \\
\hline 33 & 53 & 45.20 & 85.28 & 83 & 40 & 33.45 & 83.63 \\
\hline 34 & 35 & 30.77 & 87.91 & 84 & 36 & 30.36 & 84.33 \\
\hline 35 & 36 & 45.95 & 72.36 & 85 & 56 & 51.37 & 81.73 \\
\hline 36 & 31 & 25.13 & 81.06 & 86 & 51 & 55.98 & 90.24 \\
\hline 37 & 27 & 21.58 & 79.93 & 87 & 26 & 21.65 & 83.27 \\
\hline 38 & 54 & 61.22 & 86.63 & 88 & 24 & 22.31 & 92.96 \\
\hline 39 & 29 & 36.85 & 72.93 & 89 & 46 & 39.25 & 85.33 \\
\hline 40 & 30 & 25.76 & 85.87 & 90 & 45 & 52.74 & 82.80 \\
\hline 41 & 45 & 36.12 & 80.27 & 91 & 40 & 36.48 & 91.20 \\
\hline 42 & 28 & 25.11 & 89.68 & 92 & 41 & 35.96 & 87.71 \\
\hline 43 & 21 & 25.30 & 79.52 & 93 & 30 & 36.78 & 77.40 \\
\hline 44 & 40 & 46.55 & 83.63 & 94 & 32 & 38.10 & 80.94 \\
\hline 45 & 32 & 27.37 & 85.53 & 95 & 28 & 23.16 & 82.71 \\
\hline 46 & 53 & 48.85 & 92.17 & 96 & 21 & 23.51 & 88.05 \\
\hline 47 & 42 & 47.36 & 87.24 & 97 & 55 & 58.32 & 93.96 \\
\hline 48 & 25 & 20.14 & 80.56 & 98 & 52 & 46.28 & 89.00 \\
\hline 49 & 29 & 34.88 & 79.72 & 99 & 29 & 33.17 & 85.62 \\
\hline 50 & 49 & 42.92 & 87.59 & 100 & 37 & 44.85 & 78.78 \\
\hline
\end{tabular}


Table 2. Accuracy of the linear model to estimate number of tillers for $k=70 \mathrm{DAS}$

\begin{tabular}{|c|c|c|c|c|c|c|c|}
\hline Samples & $\begin{array}{l}\text { Actual tiller } \\
\text { number }\end{array}$ & $\begin{array}{c}\text { Predicted } \\
\text { tiller number }\end{array}$ & $\begin{array}{c}\text { Accuracy } \\
(\%)\end{array}$ & Samples & $\begin{array}{l}\text { Actual tiller } \\
\text { number }\end{array}$ & $\begin{array}{l}\text { Predicted } \\
\text { tiller number }\end{array}$ & $\begin{array}{c}\text { Accuracy } \\
(\%)\end{array}$ \\
\hline 1 & 19 & 23.11 & 78.37 & 51 & 39 & 36.18 & 92.77 \\
\hline 2 & 52 & 48.21 & 92.71 & 52 & 29 & 38.33 & 67.83 \\
\hline 3 & 30 & 21.04 & 70.13 & 53 & 56 & 42.55 & 75.98 \\
\hline 4 & 45 & 37.30 & 82.89 & 54 & 42 & 38.54 & 91.76 \\
\hline 5 & 60 & 53.19 & 88.65 & 55 & 21 & 31.31 & 50.90 \\
\hline 6 & 26 & 35.23 & 64.50 & 56 & 36 & 42.36 & 82.33 \\
\hline 7 & 48 & 50.21 & 95.40 & 57 & 41 & 33.55 & 81.83 \\
\hline 8 & 38 & 30.66 & 80.68 & 58 & 29 & 30.32 & 95.45 \\
\hline 9 & 41 & 33.23 & 81.02 & 59 & 36 & 26.10 & 72.50 \\
\hline 10 & 29 & 22.45 & 77.41 & 60 & 30 & 38.85 & 70.50 \\
\hline 11 & 41 & 36.87 & 89.93 & 61 & 39 & 41.66 & 93.18 \\
\hline 12 & 53 & 56.43 & 93.53 & 62 & 41 & 30.46 & 74.29 \\
\hline 13 & 19 & 23.16 & 78.11 & 63 & 27 & 23.11 & 85.59 \\
\hline 14 & 41 & 53.72 & 68.98 & 64 & 37 & 31.74 & 85.78 \\
\hline 15 & 33 & 26.95 & 81.67 & 65 & 29 & 22.84 & 78.76 \\
\hline 16 & 55 & 63.26 & 84.98 & 66 & 33 & 22.17 & 67.18 \\
\hline 17 & 29 & 32.26 & 88.76 & 67 & 33 & 39.21 & 81.18 \\
\hline 18 & 40 & 30.28 & 75.70 & 68 & 42 & 50.32 & 80.19 \\
\hline 19 & 43 & 40.82 & 94.93 & 69 & 50 & 47.35 & 94.70 \\
\hline 20 & 39 & 35.15 & 90.12 & 70 & 35 & 39.12 & 88.23 \\
\hline 21 & 52 & 50.95 & 97.98 & 71 & 42 & 49.33 & 82.55 \\
\hline 22 & 60 & 53.72 & 89.53 & 72 & 31 & 32.13 & 96.35 \\
\hline 23 & 19 & 20.82 & 90.42 & 73 & 49 & 38.79 & 79.16 \\
\hline 24 & 29 & 25.63 & 88.38 & 74 & 41 & 47.16 & 84.98 \\
\hline 25 & 45 & 42.41 & 94.24 & 75 & 25 & 21.61 & 86.44 \\
\hline 26 & 36 & 42.11 & 83.03 & 76 & 38 & 26.75 & 70.39 \\
\hline 27 & 28 & 20.18 & 72.07 & 77 & 47 & 41.30 & 87.87 \\
\hline 28 & 54 & 55.03 & 98.10 & 78 & 28 & 26.81 & 95.75 \\
\hline 29 & 53 & 51.12 & 96.45 & 79 & 46 & 49.22 & 93.00 \\
\hline 30 & 37 & 32.22 & 87.08 & 80 & 45 & 51.64 & 85.24 \\
\hline 31 & 41 & 49.81 & 78.51 & 81 & 47 & 35.55 & 75.64 \\
\hline 32 & 37 & 27.86 & 75.30 & 82 & 31 & 40.92 & 68.00 \\
\hline 33 & 27 & 25.20 & 93.33 & 83 & 40 & 33.66 & 84.15 \\
\hline 34 & 29 & 30.77 & 93.90 & 84 & 39 & 30.06 & 77.07 \\
\hline 35 & 33 & 40.95 & 75.91 & 85 & 52 & 51.37 & 98.79 \\
\hline 36 & 38 & 35.13 & 92.44 & 86 & 31 & 40.08 & 70.71 \\
\hline 37 & 46 & 41.48 & 90.17 & 87 & 46 & 39.65 & 86.20 \\
\hline 38 & 43 & 41.28 & 96.00 & 88 & 22 & 22.31 & 98.59 \\
\hline 39 & 50 & 45.85 & 91.70 & 89 & 33 & 39.25 & 81.06 \\
\hline 40 & 59 & 52.16 & 88.41 & 90 & 41 & 50.04 & 77.95 \\
\hline 41 & 37 & 36.12 & 97.62 & 91 & 46 & 40.48 & 88.00 \\
\hline 42 & 22 & 25.81 & 82.68 & 92 & 29 & 35.06 & 79.10 \\
\hline 43 & 21 & 25.30 & 79.52 & 93 & 30 & 36.30 & 79.00 \\
\hline 44 & 39 & 36.75 & 94.23 & 94 & 37 & 38.60 & 95.68 \\
\hline 45 & 28 & 27.37 & 97.75 & 95 & 45 & 33.16 & 73.69 \\
\hline 46 & 20 & 28.25 & 58.75 & 96 & 53 & 50.51 & 95.30 \\
\hline 47 & 49 & 47.36 & 96.65 & 97 & 50 & 58.32 & 83.36 \\
\hline 48 & 23 & 20.46 & 88.95 & 98 & 23 & 19.28 & 83.83 \\
\hline 49 & 36 & 34.88 & 96.89 & 99 & 20 & 29.37 & 53.15 \\
\hline 50 & 58 & 50.92 & 87.79 & 100 & 37 & 42.82 & 84.27 \\
\hline
\end{tabular}

